\title{
La aplicación del principio del equilibrio económico a contratos estatales sometidos al régimen normativo del derecho privado
}

Manuela Canal-Silva ${ }^{1}$

\section{RESUMEN}

En vista de la importancia del equilibrio económico del contrato dentro del marco de la contratación pública, el presente artículo pretende demostrar la procedencia de su aplicación a los contratos estatales sometidos al régimen del derecho privado. Mediante la reflexión y el estudio de la jurisprudencia sobre el tema se presentarán los principales motivos expuestos por las providencias que apoyan la tesis planteada. Se exponen así los temas del interés colectivo y los preceptos constitucionales como bases de este principio del equilibrio económico. Para luego examinar la conmutatividad del contrato y el debate frente a la consideración del equilibrio económico como un principio transversal al derecho público y privado.

Palabras clave: equilibrio económico del contrato, contrato estatal, jurisprudencia, derecho privado, principios constitucionales.

1 Docente investigadora, Departamento de Derecho Administrativo, Universidad Externado de Colombia, Bogotá, Colombia. Correo-e: manuela.canal.silva@gmail.com Fecha de recepción: 21 de diciembre de 2015. Fecha de modificación: 5 de mayo de 2016. Fecha de aceptación: 16 de mayo de 2016. Para citar el artículo: Canal-Silva, M. (2016). La aplicación del equilibrio económico a contratos estatales sometidos al régimen normativo de derecho privado. Revista digital de Derecho Administrativo n. ${ }^{\circ} 15$, primer semestre, Universidad Externado de Colombia, pp. 143-161. DOI: http://dx.doi.org/10.18601/21452946.n15.08 


\section{Application of the Economic Equilibrium to Public Procurements Subject to Private Law}

\section{ABSTRACT}

The purpose of this research is to demonstrate the practical application of the economic equilibrium to public procurements subject to Private Law and, through the examn of decisions from the Colombian State Council and arbitral awards, provide arguments in favor of this thesis. This paper starts with an analysis of the legal and constitutional framework of the economic balance of contracts, prior to present the debate around the consideration of the economic equilibrium as a principle applicable to both Public and Private Law.

Keywords: Economic Equilibrium of the Contract, Public Procurement, Case Law, Private Law, Constitutional Principles.

\section{INTRODUCCIÓN}

Dentro del marco de la contratación estatal, el equilibrio económico juega un papel protagónico. Lo anterior, no solamente porque este tiene la envergadura de principio jurídico e ilumina así todo el régimen de la contratación pública en Colombia, sino porque además constituye una temática ampliamente discutida en los estrados judiciales. Y, para mencionar el escenario de la justicia arbitral, en este existen actualmente un gran número de procesos en trámite referentes a la contratación, y una parte considerable de las demandas incluyen, dentro de sus pretensiones, la solicitud de declaraciones y condenas relacionadas con el desequilibrio financiero del contrato.

Si bien existe una corriente que considera que a los contratos estatales cobijados por el régimen de derecho privado no les son aplicables las nociones de rompimiento y restablecimiento del equilibrio económico tratadas por el derecho público, el presente escrito pretende demostrar lo contrario mediante una reflexión respecto del desarrollo jurisprudencial sobre la materia.

Dicha corriente disidente afirma que en el derecho privado "no hay garantía alguna de mantenimiento de la ecuación económica que surge al contratar" (Tribunal de Arbitraje, 2003, Gases de Boyacá y Santander contra Ecogas y Ecopetrol)2, pues esta se encuentra circunscrita al ámbito del derecho administrativo. Para

2 "En derecho privado, en contraste con el derecho público, no hay garantía alguna de mantenimiento de la ecuación económica que surge al contratar, ni garantía de rentabilidad esperada, y al respecto se expresa: Ha de recordarse que a diferencia del contrato estatal sometido al Derecho Administrativo, en la contratación privada ( $y$ por supuesto en el contrato estatal sometido al derecho privado) no se garantiza el mantenimiento de la ecuación económica 
comprender esta tesis, antes de entrar en materia, resulta ilustrativo referirse al pronunciamiento del Consejo de Estado de 28 de septiembre de 2011 (exp. 15.476), en el que se dirime una controversia surgida dentro de un contrato de comercialización, regido por las normas del derecho privado. En la mencionada providencia, la corporación sostiene que la regla general en el derecho privado está orientada a proteger la voluntad libremente expresada por las partes en el contrato.

En este sentido, "ante posibles desequilibrios en el valor real de las prestaciones $[\ldots]$ se esté en todo caso a lo convenido; es decir, los riesgos y vicisitudes del negocio, en principio, son asumidos por las partes en los términos inicialmente previstos porque el contrato es ley para ellas". Dicha situación sólo puede ser modificada excepcionalmente por un nuevo acuerdo entre los extremos negociales o en los contados casos en los que el ordenamiento lo autorice. En aras de resolver la pretensión atinente al restablecimiento de la equivalencia económica del contrato, la Sala decide, a nuestro juicio erradamente, que el principio del equilibrio económico del contrato concebido por el ordenamiento contractual administrativo no le resulta aplicable al contrato en cuestión. Lo anterior, en vista de que la disputa debe dirimirse con base en las reglas civiles y mercantiles, en las cuales reina el axioma de que el contrato es ley para las partes (art. 1602 CC).

En contraposición al panorama del derecho privado, en el ámbito público la legislación administrativa ha desarrollado ampliamente el principio de la ecuación financiera del contrato, mediante el cual se persigue la protección del interés colectivo inherente al contrato estatal (Consejo de Estado, 2011, exp. 15.476). Contrario a lo establecido por la sentencia previamente estudiada, a continuación se expondrá y se analizará una línea jurisprudencial nutrida por providencias del Consejo de Estado, así como por laudos arbitrales ${ }^{3}$, mediante la cual se pretende demostrar que las normas presentes en el ordenamiento contractual administrativo son aplicables a cualquier contrato público, al margen de las normas que lo gobiernen. Así, no sólo se presentarán contraargumentos frente a las consideraciones exhibidas por la parte disidente, sino que se expondrán los motivos plasmados por la justicia ordinaria y arbitral que defienden la tesis en cuestión (Leyex, 2014).

estructurada al perfeccionarse el negocio" (Tribunal de Arbitraje, 2003, Gases de Boyacá y Santander contra Ecogas y Ecopetrol, resaltado fuera de texto).

3 "Si bien las decisiones arbitrales no constituyen jurisprudencia, en el sentido lato de que ha de entenderse por fuente formal del derecho, por cuanto ellas no provienen de un órgano del poder público, desde el punto de vista de la doctrina sí representan un valioso aporte a la interpretación y la aplicación del derecho, que es necesario poner a disposición de árbitros, jueces, abogados y estudiantes" (BEJARANO, 2012, p. 19). 


\section{APROXIMACIÓN AL CONCEPTO DE EQUILIBRIO ECONÓMICO DEL CONTRATO}

En primer lugar, corresponde exponer qué ha entendido el supremo juez administrativo sobre la noción de equilibrio económico del contrato. Debe destacarse que alrededor de su definición no ha existido mayor debate jurisprudencial. De hecho, acorde a la corporación, se afirma que el equilibrio del contrato "no es otra cosa que el mantenimiento durante la ejecución del mismo, de la equivalencia entre obligaciones y derechos que se estableció entre las partes al momento de su celebración" (Consejo de Estado, 2003, exp. 15.119). Dicha equivalencia entre las prestaciones de los extremos contractuales ${ }^{4}$ puede romperse durante la ejecución del acuerdo por la ocurrencia de diversas circunstancias, las cuales pueden causar mayor onerosidad en el cumplimiento de las obligaciones de una de las partes. Es en ese escenario donde se alteran las condiciones económicas pactadas y entra en juego el deber de restablecer su equilibrio financiero (Consejo de Estado, 2004, exp. 14.043).

La institución en cuestión se fundamenta en la ecuación contractual, consagrada en el artículo 27 de la Ley 80 de 1993, disposición que resulta forzoso transcribir ${ }^{5}$ :

Artículo 27. De la Ecuación Contractual. En los contratos estatales se mantendrá la igualdad o equivalencia entre derechos y obligaciones surgidos al momento de proponer o de contratar, según el caso. Si dicha igualdad o equivalencia se rompe por causas no imputables a quien resulte afectado, las partes adoptarán en el menor tiempo posible las medidas necesarias para su restablecimiento.

Para tales efectos, las partes suscribirán los acuerdos y pactos necesarios sobre cuantías, condiciones y forma de pago de gastos adicionales, reconocimiento de costos financieros e intereses, si a ello hubiere lugar, ajustando la cancelación a las disponibilidades de la apropiación de que trata el numeral 14 del artículo 25. En todo caso, las entidades deberán adoptar las medidas necesarias que aseguren la efectividad de estos pagos y reconocimientos al contratista en la misma o en la siguiente vigencia de que se trate.

4 La equivalencia entre las obligaciones y los derechos de las partes debe entenderse "desde un punto de vista relativo, entendiéndose por tal el valor subjetivo que para cada una de las partes tiene la prestación de otra, valoración expresada en el contrato y que, en virtud del principio de la autonomía de la voluntad debe ser respetada" (GRANADILLO, 1990, pp. 5 ss.).

5 Aparte del artículo citado, el equilibrio económico del contrato en el marco legislativo de la contratación estatal se encuentra regulado expresamente por los artículos $4 .{ }^{\circ}$, numerales 3,8 y $9,5^{\circ}{ }^{\circ}$, numerales 1 y 14,25 , numerales 13 y 14,26 , numeral 2,28 y 50 de la Ley 80 de 1993, en consonancia con el artículo 16 de la Ley 446 de 1998. 
La ecuación contractual descansa sobre una "noción más igualitaria del contrato estatal, con relación al contrato administrativo clásico" (Benavides, 2002, p. 129) y constituye un principio fundamental de la responsabilidad para la conservación de las prestaciones inicialmente pactadas. Así, nace en cabeza de las partes y del juez la obligación de restablecer dicha equivalencia en caso de presentarse eventos que la quiebren de manera grave (Ospina, 2013, pp. 175-176).

Resulta oportuno anotar que nos encontramos en el marco de un contrato administrativo, en donde los intereses de la entidad pública y del particular son divergentes. Pues bien, mediante la celebración del acuerdo, la entidad pública busca el cumplimiento de los fines estatales, la prestación de los servicios públicos y la garantía de los derechos e intereses de los administrados, mientras que el contratista persigue una determinada utilidad personal. Pese a sus discordantes incentivos, acorde al Estatuto General de la Contratación, las dos partes del acuerdo deben colaborar entre sí para llevar de este modo a feliz término el contrato celebrado ${ }^{6}$. En este orden, "el contrato estatal debe entonces colmar las expectativas de uno y otro cocontratante, para lo cual se ha previsto la conservación de la ecuación financiera del contrato"7 (Consejo de Estado, 2004, exp. 14.043).

Así las cosas, cuando la conmutatividad de las prestaciones establecida en la celebración del contrato resulte gravemente afectada, nace tanto para el contratista ${ }^{8}$ como para la Administración ${ }^{9}$ el derecho al restablecimiento de la ecuación financiera del contrato ${ }_{i}$ correlativamente, surge en cabeza del cocontratante correspondiente el deber de la restauración del mismo ${ }^{10}$.

6 Ley 80 de 1993: "Artículo 3.- De los Fines de la Contratación Estatal. Los servidores públicos tendrán en consideración que al celebrar contratos y con la ejecución de los mismos, las entidades buscan el cumplimiento de los fines estatales, la continua y eficiente prestación de los servicios públicos y la efectividad de los derechos e intereses de los administrados que colaboran con ellas en la consecución de dichos fines.

"Los particulares, por su parte, tendrán en cuenta al celebrar y ejecutar contratos con las entidades estatales que, además de la obtención de utilidades cuya protección garantiza el Estado, colaboran con ellas en el logro de sus fines y cumplen una función social que, como tal, implica obligaciones".

7 Ver también Consejo de Estado, Sala de lo Contencioso Administrativo, Sección Primera. Sentencia de 29 de abril de 2010. C.P.: Rafael Ostau de Lafont.

8 Ley 80 de 1993. "Artículo 5.- De los Derechos y Deberes de los Contratistas. Para la realización de los fines de que trata el artículo $3 .^{\circ}$ de esta Ley, los contratistas:

"1. ${ }^{\circ}$ Tendrán derecho a recibir oportunamente la remuneración pactada y a que el valor intrínseco de la misma no se altere o modifique durante la vigencia del contrato...".

9 Ley 80 de 1993. "Artículo 4.- De los Derechos y Deberes de las Entidades Estatales. Para la consecución de los fines de que trata el artículo anterior, las entidades estatales:

"[...]

"3. 일 Solicitarán la actualización o la revista de los precios cuando se produzcan fenómenos que alteren en su contra el equilibrio económico o financiero del contrato".

10 Ley 80 de 1993. "Artículo 4. - De los Derechos y Deberes de las Entidades Estatales. Para la consecución de los fines de que trata el artículo anterior, las entidades estatales: 
Corresponde ahora enunciar los detonantes que dan vía a la ruptura de la ecuación financiera. En la Exposición de motivos del proyecto de la Ley 80 de 1993 estos se dividen en dos grupos. De acuerdo al artículo 5. ${ }^{\circ}$ del Estatuto Contractual, los supuestos de la ruptura de la ecuación del acuerdo pueden ser: (i) "causas imputables a las entidades públicas" o (ii) "hechos imprevisibles y extraños a las partes" (Benavides, 2002, p. 118).

Mientras que dentro de las causas imputables a la Administración se ubican el incumplimiento de las entidades estatales, el ejercicio de las prerrogativas contractuales del poder público ${ }^{11}$ y el hecho del príncipe ${ }^{12}$; el segundo grupo, correspondiente a los hechos imprevistos y ajenos a las partes, se identifica con la aplicación de la teoría de la imprevisión ${ }^{13-14}$.

Así, nuestro ordenamiento contractual administrativo consagra las causas de ruptura del equilibrio financiero y su correspondiente solución, referente al restablecimiento de la ecuación económica. De este modo, el equilibrio financiero constituye un eje fundamental de la contratación administrativa y, gracias a la expedición de la Ley 80 de 1993, la obligación de su mantenimiento es una norma de imperativo cumplimiento para las partes (Consejo de Estado, 1996, exp. 10.151). De ahí que mediante la garantía de la equivalencia de derechos y obligaciones el Estado asegura la prestación del servicio público en condiciones de continuidad y eficiencia (Verano, 2012, p. 232).

\section{DESARROLLO JURISPRUDENCIAL. FUNDAMENTOS DE LA APLICACIÓN DEL EQUILIBRIO ECONÓMICO A TODO CONTRATO ESTATAL, AL MARGEN DE SU RÉGIMEN NORMATIVO}

Una vez aclarado el concepto de equilibrio económico contractual, es perentorio presentar la evolución jurisprudencial respecto a la aplicación de tal principio a cualquier contrato estatal, independientemente del régimen normativo que

"[...]

8. Adoptarán las medidas necesarias para mantener durante el desarrollo y ejecución del contrato las condiciones técnicas, económicas y financieras existentes al momento de proponer en los casos en que se hubiere realizado licitación o concurso, o de contratar en los casos de contratación directa. Para ello utilizarán los mecanismos de ajuste y revisión de precios, acudirán a los procedimientos de revisión y corrección de tales mecanismos si fracasan los supuestos o hipótesis para la ejecución y pactarán intereses moratorios".

11 El cual comprende el ejercicio de interpretación, modificación y terminación unilaterales del contrato.

12 Ver Marienhoff (1966, p. 187).

13 Para un estudio más profundo de las causales de modificación de la ecuación contractual, ver BENAVIDES (2002, pp. 118 ss.).

14 Respecto de la teoría de la imprevisión, ver BerCAITZ (1952, p. 329). 
se le aplique. A continuación se expondrán los principales motivos por los cuales tanto la justicia ordinaria, encabezada por el Consejo de Estado, como la justicia arbitral han defendido el restablecimiento de la ecuación del contrato estatal gobernado por las normas propias del derecho privado.

Inicialmente se presentará al interés colectivo como piedra angular no sólo de la actividad contractual administrativa, sino del mismo equilibrio económico del contrato, para luego hacer referencia a las bases constitucionales de dicho principio. Posteriormente se estudiará la conmutatividad del contrato y, para finalizar, se abrirá el debate frente a la consideración del equilibrio económico como un principio transversal al derecho público y privado.

\section{A. EL INTERÉS GENERAL COMO RAZÓN DE SER DE LA ACTIVIDAD CONTRACTUAL ADMINISTRATIVA Y DE LA ECUACIÓN FINANCIERA DEL CONTRATO ESTATAL}

Antes de entrar en materia corresponde analizar los contratos celebrados entre una entidad pública y un particular, cuyo régimen de contratación está informado por el derecho privado, pues estos constituyen el objeto de estudio del presente escrito. Luego se expondrán los motivos legales que determinan el carácter de contratos estatales de los acuerdos en cuestión.

Con este fin en mente debe ponerse de relieve el criterio orgánico establecido por el Estatuto General de Contratación de la Administración Pública (arts. $1 .{ }^{\circ}, 2 .^{\circ}$ y 32 ), acorde al cual un contrato se considera estatal cuando una de sus partes es una entidad pública. Dicho planteamiento es confirmado por el Consejo de Estado en Sentencia de 3 de febrero de 2010 (exp. 19.526), donde se recalca la adopción del criterio orgánico por la legislación en materia de contratación administrativa. En este orden de ideas, resulta irrelevante el régimen de derecho aplicable a un acuerdo, pues mientras una de las partes contractuales sea una entidad pública este calificará como estatal.

De conformidad con lo anterior, siendo este tipo de acuerdos contratos públicos, pese a su régimen de derecho privado, les son aplicables los principios de la contratación estatal. Uno de estos principios básicos coincide con el equilibrio económico del contrato, pues este se relaciona directamente con el cumplimiento del interés general como fundamento y fin último de la actividad contractual ${ }^{15}$.

En suma, el sometimiento al derecho privado no les quita a los contratos objeto de estudio su naturaleza estatal, y todo contrato público envuelve el cumplimiento de un interés colectivo. Esta circunstancia, a su vez, posibilita el restablecimiento del equilibrio financiero de estos contratos. Así lo confirma 
la providencia de 26 de julio de 2012 (Consejo de Estado, exp. 22.756), citada previamente:

En el caso concreto, la Sala aprecia que no obstante el sometimiento al derecho civil y comercial del contrato en cuestión, la contratación de estudios para rehabilitación y construcción de obras de infraestructura vial claramente involucra el interés general y la utilidad social, no solo en atención a la definición de naturaleza del contrato transcrita, sino también en consideración al derecho positivo nacional que de manera expresa las tipifica en el artículo 58 de la Ley 388 de 1997. Lo anterior posibilita señalar al contratista como un colaborador del Estado que, de acuerdo con las condiciones propias del caso, puede recibir una compensación o indemnización en atención a la pérdida que hubiera experimentado por la modificación de las condiciones inicialmente acordadas.

Análogamente, también resulta útil el pronunciamiento de 27 de noviembre de 2013 (Consejo de Estado, exp. 31.431), en el que se lee:

Ahora bien, sea que se trate de un contrato estatal sometido al imperio del Estatuto de Contratación Estatal o sea que se trate de aquellos que por corresponder a una regla de excepción a su aplicación, como ocurre en el caso que ahora se examina, se encuentre[n] sometido[s] a las normas del derecho privado o a disposiciones especiales, lo cierto es que la equivalencia económica de las prestaciones contractuales constituye un principio medular que se encuentra inmerso en la legislación en materia de contratación estatal y que además lo recogen varias disposiciones del aludido derecho privado, razón por la cual debe estar presente en todas las relaciones negociales, máxime cuando uno de los extremos que la integran es una entidad de naturaleza estatal por cuya intervención se desprende que el negocio envuelve una finalidad pública, de manera que por vía de principio el equilibrio económico del contrato también está llamado a permear las relaciones contractuales sometidas al régimen de los particulares en donde una de ellas sea una persona jurídica de derecho público.

Por tanto, la Sala determinó que el principio del equilibrio económico del contrato, en virtud del interés jurídico protegido, irradia todo tipo de relación contractual independientemente del régimen normativo que se le aplique. Más aún, el principio cobra mayor importancia cuando una entidad estatal resulta parte del acuerdo, pues, de no aplicarse, se pondría en peligro la prestación de un servicio público o la satisfacción de un interés general, objeto del contrato celebrado ${ }^{16}$.

16 Ver Cámara de Comercio de Bogotá. Laudo arbitral de 19 de marzo de 1996. Conciviles contra Incora; Cámara de Comercio de Bogotá. Laudo arbitral de 10 de julio de 2000. Occel contra la Nación-Ministerio de Comunicaciones; Consejo de Estado, Sala de lo Contencioso Administrativo, Sección Tercera. Sentencia de 18 de septiembre de 2003, exp. 15.119. C.P.: Ramiro Saavedra Becerra. 


\section{B. LOS PRINCIPIOS CONSTITUCIONALES COMO PILARES DEL EQUILIBRIO ECONÓMICO DEL CONTRATO}

En repetida jurisprudencia se ha hecho mención a los cimientos constitucionales de la figura de la ecuación financiera del contrato. Este es el caso de la Sentencia C-892 de 2001 expedida por la Corte Constitucional, la cual enuncia los principios que irradian tal institución:

La Administración Pública tiene el deber jurídico de restablecer el sinalagma económico del contrato y entrar a satisfacer los derechos del contratista afectado por los mayores costos, dando así aplicación a los principios constitucionales de justicia conmutativa (art..$^{\circ}$ ), igualdad (art. 13) y garantía de los derechos adquiridos (art. 58).

Por su parte, la Sentencia de 26 de julio de 2012 del Consejo de Estado (exp. $22.756)$ resulta ilustrativa sobre este tema. En esta se considera que, independientemente de la inaplicación de la Ley 80 de 1993 a un contrato estatal, en el ordenamiento colombiano existen suficientes elementos para volver a este acuerdo "susceptible de análisis judicial y de condena en contra de la entidad, frente a la demanda presentada por el contratista para obtener el restablecimiento del equilibrio, una vez probados debidamente los supuestos de hecho correspondientes" (ibíd.). En este sentido, el fallo hace referencia a las normas constitucionales como pilares de nuestro ordenamiento y afirma:

... la perspectiva constitucional (actúa) como lente obligatorio para observar lo jurídico (e) impone al intérprete administrativo, civil, penal, etc., un rumbo de coherencia hermenéutica inmanente al entendimiento del ordenamiento jurídico como sistema. En tal sentido, la administración de justicia habrá de apreciar el conjunto de disposiciones legales con la extensión y, al mismo tiempo, con la restricción, que las normas constitucionales definen (Consejo de Estado, 2007, exp. AP-369). La Sala considera que los artículos constitucionales que consagran la buena fe, la solidaridad y la prohibición de abuso de los derechos serían la fuente indicada.

Posteriormente, en reciente pronunciamiento (Consejo de Estado, 2014, exp. 32.796), la corporación retoma el tema al estudiar la procedencia de la aplicación del equilibrio económico a un contrato celebrado por una empresa industrial y comercial del Estado, gobernado por el derecho privado. El Consejo de Estado determina que el estar regido el referido contrato por las normas del derecho privado no releva a las partes de conservar la equivalencia de las cargas prestacionales asumidas por las mismas.

En referencia a los fundamentos constitucionales que sustentan el equilibrio financiero, la providencia en cuestión afirma que los principios consagrados en la Carta Fundamental iluminan todas las actividades del Estado y, por lo 
tanto, resultan aplicables a cualquier contrato administrativo, al margen de las normas a las que esté sometido:

Al respecto no puede perderse de vista que la Constitución Política consagra diversas reglas y principios que irradian toda la actividad del Estado, los cuales sin duda resultan de obligatoria observancia para todas las entidades públicas que forman parte de su estructura, independientemente de que el régimen de contratación de algunas de ellas lo constituyan las normas del derecho privado. Desde esta perspectiva, el hecho de que su régimen de contratación esté informado por el derecho de los particulares, de ningún modo se puede entender como una patente para inobservar los principios constitucionales de igualdad, moralidad, eficacia, economía, celeridad, imparcialidad, libre concurrencia y publicidad, entre otros, en el desarrollo de todas las actividades encaminadas al cumplimiento de las funciones asignadas por la Ley y aquellas que se requieran para alcanzar de manera cabal su objeto principal.

Cabe destacar que dentro de las sentencias reseñadas se hace especial mención a los principios de buena $\mathrm{fe}^{17}$ y equidad como pilares de la garantía del equilibrio financiero del contrato. En efecto, desde 1972 el Consejo de Estado ha afirmado que "la regla de que los contratos deben ejecutarse de buena fe no es exclusiva del derecho privado" (exp. 561), pues, al ser un principio general mediante el que "se adopta el valor ético y social de la confianza" (Corte Constitucional, Sentencia C-892 de 2001), este también se aplica directamente en el ámbito del derecho público. Así, de su aplicación se deriva la protección del resultado económico perseguido por las partes dentro del marco de la contratación pública.

A propósito del principio de equidad se ha señalado que este ocupa un lugar privilegiado dentro de la doctrina universal (particularmente en la jurisprudencia francesa). Lo anterior, en vista de que la equidad, con el fin de contrarrestar los poderes exorbitantes inherentes a la Administración, está encaminada a proteger el "equilibrio de recíprocas prestaciones en cualquier contrato (aunque con inicial referencia al contrato administrativo)" (Consejo de Estado, 1979, exp. 2.742).

Es preciso concluir que debe entenderse a la actividad contractual del Estado como una actividad administrativa en su esencia y, como tal, esta debe observar los principios consagrados en el artículo $209 \mathrm{CP}$, así como aquellos establecidos por el Código de Procedimiento Administrativo y de lo Contencioso Administrativo. Dichos principios obligan a la Administración a mantener incólume el derecho en cuestión en cabeza de las partes; además, le dan el carácter de

17 Constitución Política de Colombia: "Artículo 83.- Las actuaciones de los particulares y de las autoridades públicas deberán ceñirse a los postulados de la buena fe, la cual se presumirá en todas las gestiones que aquéllos adelanten ante éstas". 
regla de orden público, la cual, por definición, no admite pacto en contrario. De ahí que, al celebrar un contrato estatal, independientemente del régimen legal de contratación que lo gobierne, bajo ninguna circunstancia está en manos de las partes hacer caso omiso del equilibrio económico del contrato.

\section{LA CONMUTATIVIDAD DEL CONTRATO COMO FUENTE DEL EQUILIBRIO ECONÓMICO}

En primer lugar, cabe referirse a la definición de conmutatividad del contrato. Para este fin, el Código Civil colombiano ofrece una aproximación a la figura haciendo énfasis en la equivalencia de las prestaciones:

Artículo 1498. Contrato conmutativo y aleatorio. El contrato oneroso es conmutativo, cuando cada una de las partes se obliga a dar o hacer una cosa que se mira como equivalente a lo que la otra parte debe dar o hacer a su vez; y si el equivalente consiste en una contingencia incierta de ganancia o pérdida, se llama aleatorio.

Ahora, para determinar si un acuerdo es conmutativo o aleatorio es preciso establecer si desde su perfeccionamiento están definidos los derechos y obligaciones en cabeza de las partes ${ }_{i}$ de estarlo, nos encontramos frente a un contrato conmutativo. Por otra parte, resulta útil revisar las características que Ospina Fernández y Ospina Acosta atribuyen al contrato conmutativo: (i) es oneroso; (ii) no es aleatorio, toda vez que la utilidad del acuerdo debe ser apreciada desde su celebración y (iii) produce prestaciones equivalentes entre sí, las cuales determinan "un cierto equilibrio en la economía del contrato" (Ospina y Ospina, 1994, p. 84).

Sólo de las características expuestas resulta razonable la reflexión repetida por providencias del Consejo de Estado y laudos arbitrales según la cual la conmutatividad del contrato constituye otro de los fundamentos de "la obligación de reconocer la compensación correspondiente al contratante que haya incurrido en mayores erogaciones para el cumplimiento del contrato" (Consejo de Estado, 2012, exp. 22.756). Lo anterior, en vista de que la conmutatividad del contrato involucra el derecho a la igualdad de las partes; en ese sentido, ningún cocontratante está obligado a soportar cargas que no le corresponden jurídicamente sin recibir la respectiva indemnización a cambio.

A propósito de la conmutatividad ${ }^{18}$ del negocio jurídico, bien expone el máximo juez administrativo en Sentencia de 2006 que esta corresponde a la regla general en los contratos celebrados por la Administración pública, "puesto que los principios que orientan la función administrativa y la contratación estatal (transparencia, economía y responsabilidad) exigen que todo contrato

18 En referencia al debate sobre la conmutatividad y aleatoriedad del contrato de concesión, ver EXPÓSITO VÉLEZ (1996). 
público verse sobre prestaciones definidas y predeterminadas" (Consejo de Estado, 2006, exp. 1.792). Por su parte, afirma la profesora Safar (2006, pp. 26 ss.) que en este tipo de contratos debe entenderse entonces una equivalencia material ${ }^{19}$ entre las prestaciones de las partes. En este sentido, "la conmutatividad se da sobre la base de referentes objetivos que nos aproximen a puntos reales de equilibrio económico y no de supuestos convencionales, derivados de la autonomía de la voluntad" (Santofimio, 2009, p. 17). Bajo este entendido, no sólo se aplica en el contrato estatal la teoría del equilibrio económico al momento de proponer o celebrar el contrato, sino que se edifica su acepción negativa, la cual se refiere a la ruptura de dicha relación objetiva balanceada, que comporta la obligación para una de las partes de restablecer el equilibrio quebrantado ${ }^{20}$.

En referencia a la posición de los tribunales de arbitramento, encontramos el Laudo de 13 de diciembre de 2007, proferido por el tribunal de arbitramento conformado para resolver las diferencias suscitadas entre ESGEM Worldwide Corporation y Termoyopal S.A. y otros. En dicho fallo el tribunal sostiene que el principio del equilibrio económico forma parte de la naturaleza misma de todo contrato conmutativo:

La garantía del equilibrio económico, según la autora citada, lleva a reconocer, de otra parte, que la buena fe y la equidad son instrumentos "en virtud de los cuales la consideración de la economía del negocio conduce a la identificación de las reglas de la relación" contractual.

La unicidad entre la regulación jurídica, plasmada en las cláusulas contractuales pactadas con arreglo a la ley, y el equilibrio económico que implica el concepto de conmutatividad de las prestaciones que las partes se comprometen mutuamente a dar o a hacer en virtud del contrato, conducen inexorablemente a considerar que el mencionado equilibrio es algo que pertenece a la naturaleza misma de todo contrato conmutativo y que, por consiguiente, se entiende incorporado a él, aún a falta de pacto expreso de las partes sobre el particular (C.C., art. 1501).

Análogamente, un laudo arbitral del mismo año (Tribunal de Arbitraje, 2007, Grodco S. en C. A. Ingenieros (iviles contra el INVIAS) establece que, al ser el equilibrio económico un principio fundamental "de todo contrato bilateral, sinalagmático o de prestaciones correlativas", este resulta aplicable a cualquier acuerdo de este tipo que "sea celebrado por los particulares, ora por una entidad estatal, trátese de un contrato regulado por las disposiciones civiles o comerciales o por el estatuto de contratación estatal".

20 Para estudiar la conmutatividad del contrato como límite a la autonomía de la voluntad de las partes, ver ESCOBAR GIL (1999). 
Los fallos del Consejo de Estado siguen la misma línea que aquellos previamente referenciados. Acorde a jurisprudencia coherente (Consejo de Estado, 2003, exp. 15.119 y Consejo de Estado, 2004, exp. 14.043), para la corporación, de la conmutatividad del contrato se deriva la equivalencia de sus prestaciones y, así, el derecho en cabeza de las partes a la conservación de la estructura original del contrato.

\section{D. ¿EL EQUILIBRIO ECONÓMICO COMO PRINCIPIO TRANSVERSAL AL DERECHO PÚBLICO Y PRIVADO?}

Otro de los motivos expuestos por la jurisprudencia para sustentar la aplicación del equilibrio económico a contratos estatales no sujetos al régimen de la Ley 80 de 1993 responde a la consideración del equilibrio financiero como un principio presente tanto en la esfera del derecho público como en aquella del derecho privado. Sin embargo, debe aclararse que, a diferencia del resto de argumentos expuestos, este ha sido ampliamente debatido tanto por la jurisprudencia como por la doctrina nacional. A continuación se plantearán las dos posturas divergentes respecto a la aplicación del principio en los dos campos del derecho.

En primer lugar, cabe mencionar que, si bien parte de la doctrina y la jurisprudencia ${ }^{21}$ ha defendido el respeto del equilibrio financiero de los contratos tanto en el ámbito privado como en el público, resultan escasos los fallos que aplican de manera práctica las figuras ideadas por el legislador para la corrección del desequilibrio económico en el ámbito de los acuerdos privados. Aclarado este hecho, analizaremos cómo ha tratado la jurisprudencia esta cuestión y el debate doctrinal al respecto.

El Consejo de Estado (2003, exp. 15.119) ha sostenido que la protección del equilibrio económico en el ámbito de los contratos privados surgió con ocasión de las situaciones de injusticia provocadas por la ciega aplicación del principio pacta sunt servanda. En el mismo sentido, afirma la doctrina que "El Código de Comercio representa un esfuerzo fundamental por rescatar el negocio jurídico de los rigores del individualismo, pues en él se introducen varios aspectos relacionados con la teoría del negocio jurídico que tiene como finalidad primordial crear o establecer una justicia contractual y equilibrar las relaciones contractuales" (Zapata y Nisimblat, 1997, p. 73). En nuestro sistema

21 "Sería un contrasentido de la justicia y la equidad considerar que el respeto por el equilibrio económico o financiero de los contratos solo se predicara en la contratación estatal regulada por la Ley 80 de 1993. Porque precisamente la ley comercial consagra para los contratos celebrados entre particulares dos disposiciones con idéntico sentido teleológico: La del artículo 868 que desarrolla la teoría de la imprevisión; y la del artículo 871, que aplica los principios de la buena fe y la equidad" (SiLva GarCía, 2007, p. 50). 
jurídico la figura de la revisión del contrato mercantil está consagrada en el artículo 868 del Código de Comercio, en los siguientes términos:

Cuando circunstancias extraordinarias imprevistas o imprevisibles, posteriores a la celebración de un contrato de ejecución sucesiva, periódica o diferida, alteren o agraven la prestación de futuro cumplimiento a cargo de una de las partes, en grado tal que le resulte excesivamente onerosa, podrá ésta pedir su revisión.

El juez procederá a examinar las circunstancias que hayan alterado las bases del contrato y ordenará, si ello es posible, los reajustes que la equidad indique; en caso contrario, el juez decretará la terminación del contrato.

Esta regla no se aplicará a los contratos aleatorios ni a los de ejecución instantánea.

En referencia al artículo citado, la corporación afirma que este establece la aplicación de la teoría de la imprevisión "cuando la ejecución de un contrato conmutativo se torna excesivamente onerosa para una de las partes, en razón a hechos sobrevinientes, extraordinarios e imprevisibles a su celebración, de forma que se autoriza su revisión por parte del juez, con el objeto de reajustar el contrato" (Consejo de Estado, 2011, exp. 15.476).

También el Laudo arbitral de 10 de noviembre de 2004 (Caracol Televisión S.A. contra Comisión Nacional de Televisión) resulta ilustrativo frente al tema en cuestión. En este fallo, luego de establecer que el citado artículo dispone los requisitos que configuran la teoría de la imprevisión, el tribunal establece que la disposición resulta aplicable también a los contratos regulados por la Ley 80 de 1993.

Hasta este punto, las providencias referenciadas establecen un régimen legislativo paralelo acerca de la aplicación del principio del equilibrio económico en las esferas de derecho público y privado. No obstante lo anterior, también existe una corriente jurisprudencial y doctrinal que defiende las diferencias entre las dos figuras. A propósito del artículo 868 C.Co., Benavides expone:

Treinta años después de la entrada en vigor del Código de Comercio, la Corte Suprema de Justicia no ha tenido ocasión de precisar la aplicación de esta norma, pero no creemos que se pueda hacer un paralelo con la aplicación de la teoría de la imprevisión del contrato administrativo clásico, dadas las particularidades de ésta última (2002, p. 133).

Por su parte, Santos (2013, p. 167) sostiene que, aunque en principio la figura de la onerosidad sobreviniente establecida en el artículo 868 C.Co. y la de la teoría de la imprevisión consagrada por la Ley 80 de 1993 parecieran idénticas, estas no lo son. Pues bien, mientras la primera únicamente procede frente a prestaciones de futuro cumplimiento, la segunda se aplica tanto a prestacio- 
nes pasadas como a prestaciones futuras (Tribunal de Arbitraje, 2012, Comisión Nacional de Televisión contra RCN Televisión S.A.).

Por último, las diferencias entre las dos instituciones son expuestas por el laudo de 24 de noviembre de 2000, proferido dentro del proceso del Consorcio Miel contra Fiduanglo. Este plantea que, no obstante sus semejanzas, las figuras son distintas por varios motivos:

En el régimen de la Ley 80, para que haya lugar a invocar el rompimiento del equilibrio contractual y a solicitar su consiguiente restablecimiento, basta simplemente con que ocurra cualquier álea anormal que lesione la conmutatividad contractual establecida por las partes, siempre, desde luego, que ella no le sea imputable a quien la sufre. En cambio, en el del Código de Comercio, no sólo es necesario un hecho o circunstancia que sobrevenga durante la ejecución del contrato, sino, además, que esa circunstancia que sobrevenga durante la ejecución del contrato, sino, además que esa circunstancia tenga la condición de ser extraordinaria e imprevista o imprevisible [sic].

De otro lado, mientras en el régimen de la Ley 80 apenas si se requiere que esa circunstancia sobreviniente afecte sin más calificativos y por ende de cualquier modo la conmutatividad originalmente acordada por las partes, en el de la ley mercantil se exige, perentoriamente, que aquélla sea de un grado tal que le haga al deudor excesivamente onerosa la ejecución de la prestación de que se trate.

Después de analizar las providencias y los laudos arbitrales referenciados, resulta evidente que el debate frente a la aplicación del principio del equilibrio financiero del contrato en el derecho privado y en el derecho público continúa abierto. Mientras una parte de la jurisprudencia ha defendido su semejanza permitiendo incluso la aplicación del artículo 868 del Código de Comercio a los contratos estatales, existe otra corriente que, pese a aceptar las semejanzas entre las figuras consagradas por dicho Código y la Ley 80 de 1993, rechaza su correspondencia al encontrar varios puntos que las singularizan.

\section{CONCLUSIÓN}

Luego de la exposición y reflexión respecto de las posturas de la justicia ordinaria y arbitral frente a nuestro objeto de investigación, es forzoso concluir que, contrario a lo planteado por parte de algunos estudiosos del tema, las dos se direccionan paralelamente hacia la misma respuesta. Así, de los fallos reseñados queda claro que, en el marco de un contrato estatal -ya sea sometido a las normas civiles y comerciales o al ordenamiento contractual administrativo-, el principio del equilibrio económico del contrato constituye una norma de imperativo cumplimiento para las partes. 
El análisis realizado resulta importante para plantear una posición distinta a la corriente disidente expuesta, pero además, en vista de los cambios políticos y legislativos constantes en nuestro país, se torna interesante el estudio de la evolución del alcance de los principios contractuales, los cuales están en continuo desarrollo.

Resulta imposible establecer con claridad el rumbo que tomará la jurisprudencia. No obstante, en virtud de las sólidas posturas de los tribunales de arbitraje y del Consejo de Estado en aras de la protección del interés general como fin último de la actividad administrativa, bien puede considerarse probable que la defensa de la aplicación del equilibrio financiero a todo contrato estatal tenga eco en el futuro.

\section{BIBLIOGRAFÍA}

\section{DOCTRINA}

ARIÑO (2007). El equilibrio financiero en el contrato administrativo. Memorias IV Jornadas de Contratación Estatal. Bogotá: Universidad de los Andes.

Bejarano GuZmán (2012). La jurisprudencia arbitral en Colombia. Bogotá: Universidad Externado de Colombia.

BenAvides (2002). El Contrato Estatal. Entre el Derecho Público y el Derecho Privado. Bogotá: Universidad Externado de Colombia.

BERCAITZ (1952). Teoría general de los contratos administrativos. Buenos Aires.

EsCObar GiL (1999). Teoría general de los contratos de la Administración Pública. Bogotá: Legis.

EXPÓSITO VÉLEZ (1996). La conmutatividad y aleatoriedad del contrato de concesión en derecho administrativo. X Jornadas de Derecho Administrativo. Incertidumbre en la contratación estatal. Bogotá: Universidad Externado de Colombia.

Granadillo (1990). Distribución de los riesgos en la contratación administrativa. Buenos Aires: Astrea.

LÓPEZ JACOISTE (1976). Sobre la aporía de la equivalencia contractual. En Estudios jurídicos en bomenaje al Profesor Federico de Castro. Madrid: Tecnos.

MarienHOff (1966). Tratado de Derecho Administrativo, t. IIIA. Buenos Aires: Abeledo-Perrot.

OsPinA FERNÁNDEZ y OsPinA ACOSTA (1994). Teoría general del contrato y de los demás actos o negocios jurídicos. Bogotá: Temis. 
OSPINA GARZÓN (2013). Alteración grave que da lugar al desequilibrio económico del contrato. Diferencia entre hecho del príncipe y la teoría de la imprevisión. Los tributos como forma de ruptura del equilibrio económico del contrato. En Los grandes fallos de la jurisprudencia administrativa colombiana. Bogotá: Universidad Externado de Colombia.

SAFAR (2006). Impacto cumulativo y equilibrio económico en el contrato estatal. Tesis de pregrado en Derecho. Bogotá: Universidad Externado de Colombia.

SANTOFimio GAMBOA (2009). El carácter conmutativo y por regla general sinalagmático del contrato estatal y sus efectos respecto de la previsibilidad del riesgo y del mantenimiento de su equilibrio económico. Revista Digital de Derecho Administrativo n. ${ }^{\circ}$ 1. Universidad Externado de Colombia, pp. 1-57. DOI: http://revistas.uexternado.edu.co/index.php/Deradm/article/view/2589/2228.

SAntos (2013). Equilibrio económico del contrato estatal. Fundamento. Teoría de la imprevisión. Metodología del restablecimiento. En Los grandes fallos de la jurisprudencia administrativa colombiana. Bogotá: Universidad Externado de Colombia.

SilVA GARCía (2007). Una aproximación a la visión de la corrección del desequilibrio contractual desde la perspectiva de la jurisprudencia arbitral. Revista e-Mercatoria, vol. 6, n. ${ }^{\circ}$ 2, Universidad Externado de Colombia, pp. 1-64. DOI: http://revistas. uexternado.edu.co/index.php/emerca/article/view/2062/1849.

VERANO (2012). La gestión jurídica del riesgo en el contrato de concesión de obra pública. Tesis doctoral en Derecho. Bogotá.

ZAPATA y NiSIMBLAT (1997). Integración de las normas comerciales y civiles en materia de obligaciones y contratos: interpretación del artículo 822 del Código de Comercio. Revista de Derecho Privado n. ${ }^{\circ}$ 19-20. Universidad de los Andes, pp. 65-116. DOI: https://derechoprivado.uniandes.edu.co/components/com_revista/archivos/ derechoprivado/pri291.pdf

\section{DOCUMENTOS DE INTERÉS}

Leyex (2014). El principio del equilibrio económico es aplicable a los contratos estatales sometidos al régimen normativo del derecho privado. Leyex. Bogotá.

El Tiempo (2014). Los tribunales donde la Nación pierde 7 de cada 10 casos. El Tiempo. Bogotá.

\section{JURISPRUDENCIA NACIONAL}

\section{Corte Constitucional}

Sentencia C-892 de 2001. M.P.: Rodrigo Escobar Gil. 


\section{Consejo de Estado}

Sala de Consulta y Servicio Civil. Concepto de 11 de marzo de 1972. Exp. 561. C.P.: Alberto Hernández Mora.

Sala de lo Contencioso Administrativo, Sección Tercera. Sentencia de 20 de septiembre de 1979. Exp. 2.742. C.P.: Jorge valencia Arango.

Sala de lo Contencioso Administrativo, Sección Tercera. Sentencia de 9 de mayo de 1996. Exp. 10.151. C.P.: Daniel Suárez Hernández.

Sala de lo Contencioso Administrativo, Sección Tercera. Sentencia de 18 de septiembre de 2003. Exp. 15.119. C.P.: Ramiro Saavedra Becerra.

Sala de lo Contencioso Administrativo, Sección Tercera. Sentencia de 26 de febrero de 2004. Exp. 14.043. C.P.: Germán Rodríguez Villamizar.

Sala de Consulta y Servicio Civil. Concepto de 12 de diciembre de 2006. Exp. 1.792. C.P.: Germán Rodríguez Villamizar.

Sala de lo Contencioso Administrativo, Sección Tercera. Sentencia de 17 de mayo de 2007. Exp. AP-369. C.P.: Ramiro Saavedra Becerra.

Sala de lo Contencioso Administrativo, Sección Tercera. Sentencia de 3 de febrero de 2010. Exp. 19.526. C.P.: Ruth Estela Correa Palacio.

Sala de lo Contencioso Administrativo, Sección Primera. Sentencia del29 de abril de 2010. C.P.: Rafael Ostau de Lafont.

Sala de lo Contencioso Administrativo, Sección Tercera, Subsección B. Sentencia de 28 de septiembre de 2011. Exp. 15.476. C.P.: Ruth Stella Correa Palacio.

Sala de lo Contencioso Administrativo, Sección Tercera, Sentencia de 26 de julio de 2012. Exp. 22.756. C.P.: Danilo Rojas Betancourth.

Sección Tercera, Subsección A. Exp. 31.431 Sentencia de 27 de noviembre de 2013.

Sala de lo Contencioso Administrativo, Sección Tercera, Subsección A. Sentencia de 12 de marzo de 2014. Exp. 32.796. C.P.: Mauricio Fajardo Gómez.

\section{Laudos arbitrales}

Cámara de Comercio de Bogotá. Laudo arbitral de 19 de marzo de 1996. Conciviles contra Incora. 
Cámara de Comercio de Bogotá. Laudo arbitral de 10 de julio de 2000. Occel contra la Nación-Ministerio de Comunicaciones.

Cámara de Comercio de Bogotá. Laudo arbitral de 24 de noviembre de 2000. Consorcio Miel contra Fiduanglo.

Cámara de Comercio de Bogotá. Laudo arbitral de 20 de agosto de 2003. Gases de Boyacá y Santander contra Ecogas y Ecopetrol.

Cámara de Comercio de Bogotá. Laudo arbitral de 10 de noviembre de 2004. Caracol Televisión S.A. contra Comisión Nacional de Televisión.

Cámara de Comercio de Bogotá. Laudo arbitral de 16 de febrero de 2007. C. I. Grodco S. en C. A. Ingenieros Civiles contra el Instituto Nacional de Vias-INVIAS.

Cámara de Comercio de Bogotá. Laudo arbitral de 13 de diciembre de 2007. ESGEM Worldwide Corporation contra Termoyopal S.A. y otros.

Cámara de Comercio de Bogotá. Laudo arbitral de 10 de febrero de 2012. Gases de Occidente S.A. ESP contra la Nación-Ministerio de Minas y Energía.

Cámara de Comercio de Bogotá. Laudo arbitral de 7 de noviembre de 2012. Comisión Nacional de Televisión (SNTV) contra RCN Televisión S.A. 